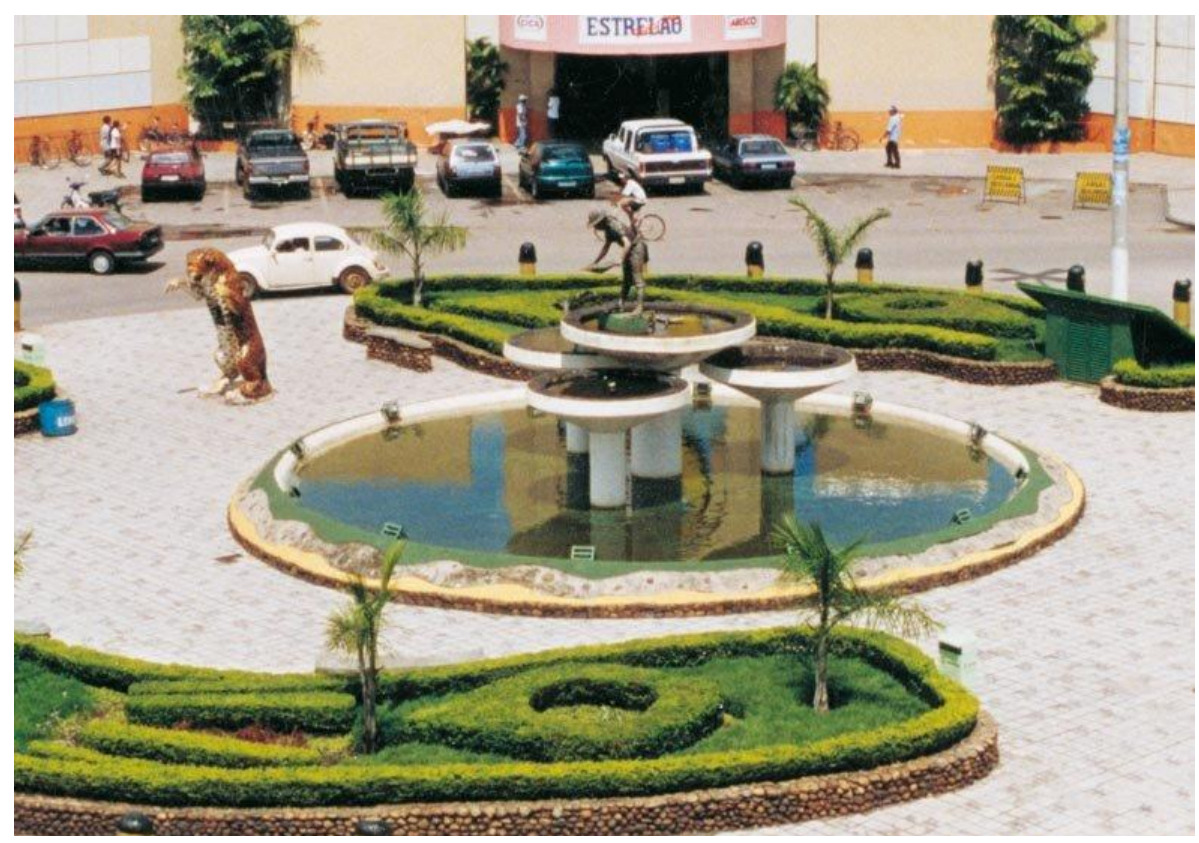

\title{
Relacão sujeito indígena/cidade: Análises para a construção de um objeto de pesquisa
}

Indigenous relation subject/ city: analysis for the construction of an object of search

Águeda Aparecida da Cruz Borges ${ }^{1}$

\section{Resumo:}

$\mathrm{O}$ artigo discute um objeto de pesquisa sobre processos de identificação, subjetivação de indígenas Xavante, em Barra do Garças-MT. Sob pressupostos da Análise de Discurso de base Materialista, o corpus heterogêneo mostra que o sujeito não índio significa, delimitando o seu espaço e o do indígena, marcando-se a diferença, o preconceito, a invisibilidade, a negação, a brasilidade, a cidadania... Contudo, na subjetivação se instaura a resistência, pois o Xavante interpela a cidade que o interpela.

Palavras-Chave: Análise de Discurso, indígenas xavante, cidade, objeto de pesquisa.

\section{Abstract}

This paper discusses an object of research on processes of identification, subjectivity of indigenous Xavante in Barra do Garças-MT. Under assumptions of Materialist Discourse Analysis, the "corpus" heterogeneous shows that the subject non-Indian means to outline its space and the indigenous, marking up the difference, prejudice, invisibility, denial, Brazilianness, citizenship ... However, the subjectivity is established strength because the Xavante challenges which challenges the city.

Keywords: Discourse Analysi, indigenous xavante, city, object search.

\footnotetext{
${ }^{1}$ Proff $^{\text {a }}$ do Curso de Letras do Instituto de Ciências Humanas e Sociais/Campus Universitário do Araguaia/Universidade Federal de Mato Grosso/UFMT, Barra do Garças-MT. Dr ${ }^{a}$. em Linguística pelo IEL/ UNICAMP. Líder do Grupo de Pesquisa: Arte, Discurso e Prática Pedagógica, (ADP) - CNPq. Endereço: Rua Jari, n 1650, Jardim Amazônia, Barra do Garças-MT. CEP: 78.600-000. E-mail: guidabcruz@hotmail.com.
} 
[...]nunca deixaremos de ser índios, eu tenho orgulho de ser índia, pelo menos sabemos de onde viemos[...] (do corpus)

A memória discursiva possui um laço estreito com a subjetivação e, de certa forma, contribui para explicar o porquê da escolha de um objeto de pesquisa com um corpus tão heterogêneo quanto o analisado na tese de doutorado que recentemente defendi.

Este texto traz apenas alguns pontos importantes, dentre as complexas discussões desenvolvidas na referida tese, convergindo para os processos de identificação/subjetivação/naturalização de indígenas Xavante ${ }^{2}$ frequentes na cidade de Barra do Garças-MT².

Uma das diferenças na abordagem dada a este trabalho é que, em relação a outras áreas que se ocupam da cidade, ou em relação ao corpo, observo o corpo indígena enredado pelo/no corpo da cidade pela linguagem. Os pressupostos teóricos são da Análise de Discurso Materialista, ressaltando o caráter revolucionário atribuído pela teoria aos estudos da linguagem, que se distancia do aspecto formal e categorizador conferido pelo estruturalismo.

A escolha do objeto de pesquisa se deve, além do meu interesse pelas questões de linguagem, de sujeito, de espaço, de corpo, de memória, ao meu encontro com um grupo de indígenas Xavante, numa antiga Rodoviária de Barra do Garças/MT, no ano de 1982. Naquele primeiro encontro, chamou-me a atenção a presença indígena no espaço da cidade, pois imaginava encontrá-los em aldeias. Esse imaginário se deve ao discurso escolar materializado na história do Brasil, sob o ponto de vista europeu, ou mesmo familiar, pela exaltação romântica, principalmente, quando se dirigiam a mim: "Vejam

\footnotetext{
${ }^{2}$ Xavante é um povo guerreiro e caçador. Vive na região do Araguaia, desde que os ancestrais atravessaram o Rio das Mortes há quase 200 anos. Resistiram à entrada das frentes de atração na década de 1940. O povo Xavante se auto denomina A'uwê Uptabi, gente verdadeira. Eles se pintam com jenipapo, carvão e urucum, tiram as sobrancelhas e os cílios, usam cordinhas nos pulsos e pernas e a gravata cerimonial de algodão. $\mathrm{O}$ corte de cabelo, os adornos e pinturas são marcas identitárias Xavante. O Warã reúne os homens adultos todos os dias, antes do nascer e ao pôr do sol para discutirem os assuntos de importância para a aldeia. (Recorte de uma entrevista com um grupo de xavantes: Supitó, Rupawe, Serezabdze intermediada pelo intérprete vice-cacique Paulo da Aldeia Etenbiritiba e Wederã , localizada nas terras indígenas Pimentel Barbosa-MT, pela Equipe Giros (2003). (sic).

${ }^{3}$ Barra do Garças localiza-se no centro geodésico do Brasil e também é conhecida como Portal da Amazônia. As primeiras notícias acerca da região se deram por conta das lendárias Minas dos Martírios, no século XVII. "Naquele período, o imenso quadrilátero barragarcense era habitado de cima abaixo por povos indígenas Bororo e Xavante". (detaque meu). http://barradogarcas.com/2010/?Secao=Municipio\&Pg=Historia. Acesso em abril de 2009.
} 
que linda, ela parece uma indiazinha!" e eu não sabia bem o motivo pelo qual me atribuíam tal aparência. Configura-se, desse modo, um retorno à memória, não como busca ao passado, lembrança, mas como memória discursiva, interdiscurso, “[...] algo que fala antes, em outro lugar e independente" (ORLANDI, 2006, p.21).

A decisão sobre um objeto para ser analisado, com fundamentação na Análise de Discurso, não é aleatória; ela nasce das nossas indagações, faz parte de um passado que pulsa em nós e se atualiza; de outro modo, é o efeito de repetição e de reconhecimento discursivo, que sempre pode ruir sob o peso de um acontecimento novo, que perturba a memória já estabelecida. É nesse espaço de retomadas, conflitos, regularizações (PÊCHEUX, 1999), que uma trajetória de pesquisa se constrói, onde o esquecimento emerge para significar o "[...] acontecimento do significante no mundo" (ORLANDI, 2001, p. 46).

Quando (re)encontrei os Xavante no 'mesmo' espaço, ou seja, no terminal rodoviário, já destituído da sua função anterior, o espaço abrigava mendigos, bêbados, prostitutas, "passantes". $\mathrm{Na}$ ocasião, mais especificamente no ano de 2003, esse (re)encontro (re)significou no acontecimento discursivo fundador deste texto.

Propus, na época, ao Projeto de pesquisa Arte, Discurso e Prática Pedagógica ADP-CNPq/2003, um subprojeto, dando enfoque à presença indígena no espaço público da cidade, principalmente, na praça do antigo terminal rodoviário, pensando, paradoxalmente, essa presença física: corpo presente, em relação às esculturas indígenas fixadas ao redor de outra praça, chamada a Praça do "Garimpeiro", conforme aparece na foto a) abaixo. Uma análise em relação a esse paradoxo pode ser encontrada em Borges $(2006)^{4}$ e, posteriormente, sobre a retirada das referidas esculturas da Praça, ver foto b) em Borges (2009) $)^{5}$.

O fato é que, desde o princípio da pesquisa, à medida da conformação do "corpus", os materiais foram mostrando o jogo entre acatar e expulsar o índio da cidade.

\footnotetext{
${ }^{4}$ BORGES, A. A.C. "A constituição discursiva sobre o índio em Barra do Garças/MT: um paradoxo na praça. In: Revista Panorâmica Multidisciplinar, nº 06. EdUFMT, Cuiabá, 2006.

BORGES, A.A.C. "Índios Xavante X não índios na cidade de Barra do Garças/MT: gestos de interpretação discursiva" In: INDURSKY, F.; FERREIRA, M. C. L. \& MITTIMANN, S. (Orgs). O Discurso na Contemporaneidade: Materialidades e Fronteiras. Claraluz, São Carlos, 2009.
} 


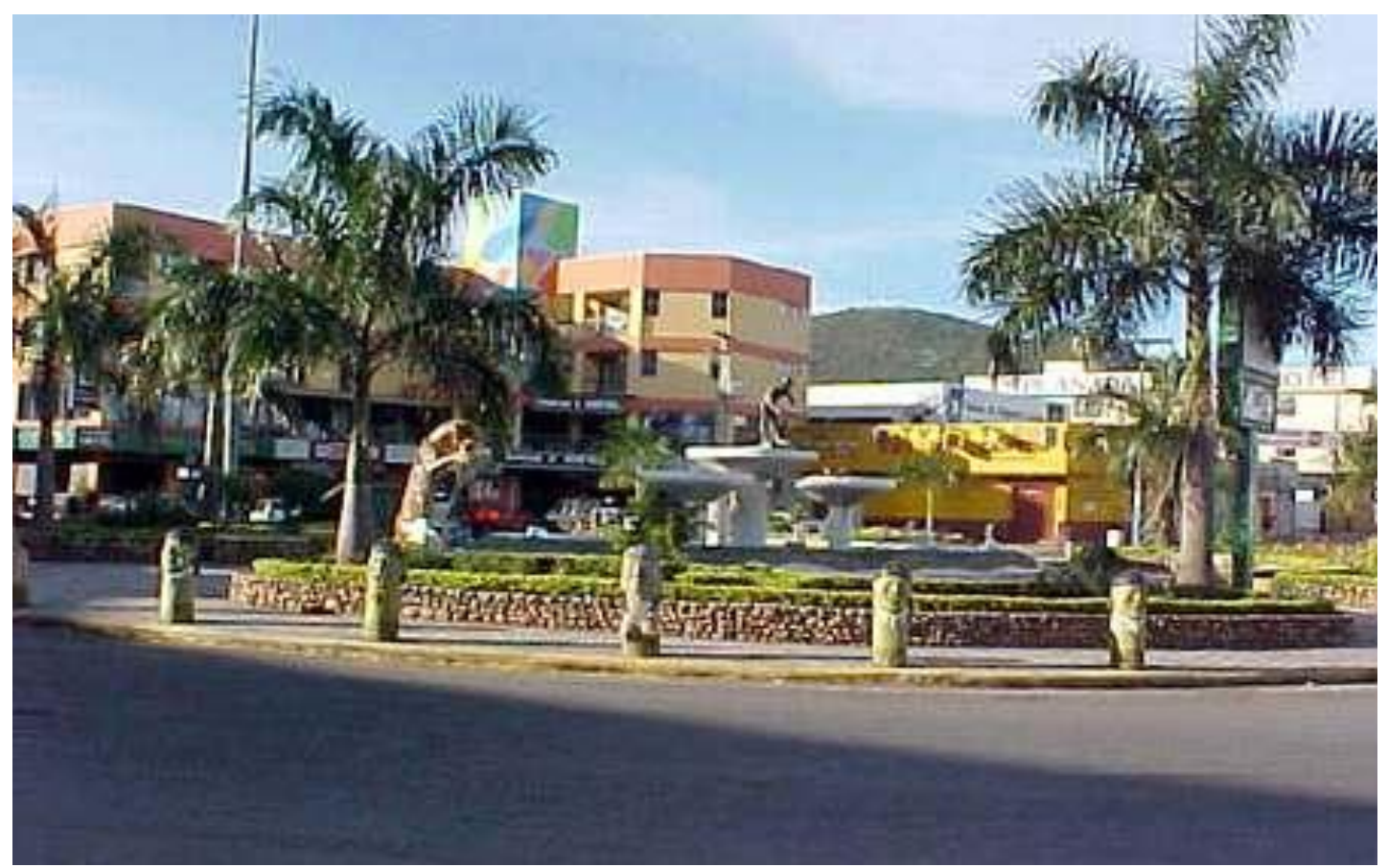

Foto a) de Anderson - exclusiva para a pesquisa ADP, em 2003.

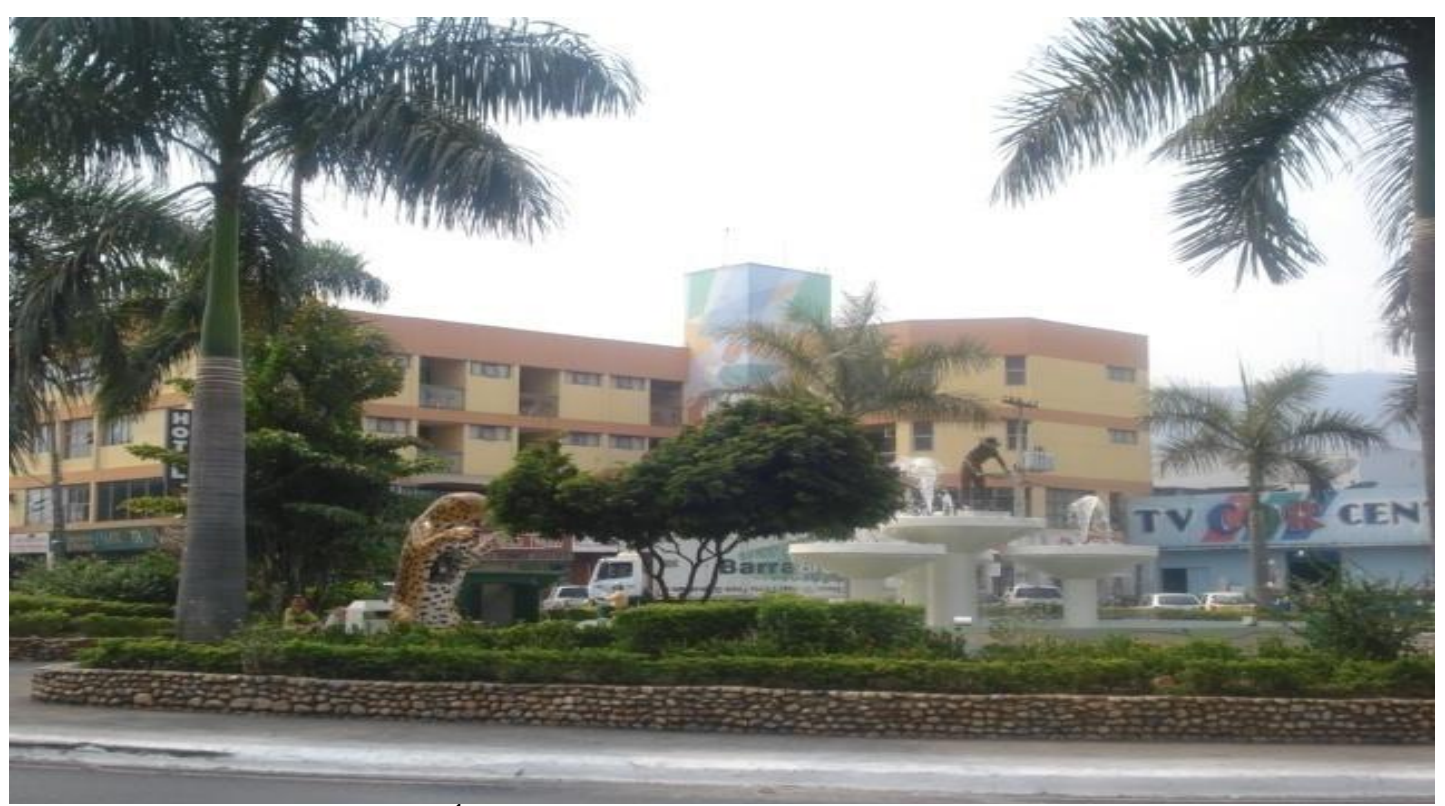

Foto b) de Ícaro - exclusiva para a pesquisa, em 13/10/2007.

É significativo retomar um dos artigos, resultado do trabalho de Iniciação

Científica (IC) desenvolvido por Borges \& Miranda (2006-2008) na citação que segue:

As posições-sujeito distintas resultam das posições variadas que os sujeitos ocupam na sociedade, que permitem dizer - ou não - determinados discursos. Numa entrevista com uma estudante de Pedagogia e professora primária (EU04), por exemplo, destacamos a preocupação da entrevistada em justificar sua visão a respeito do índio, a qual melhorou devido ao fato de estar estudando a história da educação, criticamente: 
- (...)Talvez eu tinha assim algum tempo, assim, atrás, eu tinha uma visão, assim que o índio não era uma coisa boa, eu tinha assim uma visão, assim que índio não era uma coisa boa, mas hoje inda bem que eu estou, que eu já estou mudando, assim, o próprio estudar a história da educação eu já tenho uma visão melhorzinha de índio, de que é ser índio, e já tô conseguindo, assim, valorizar.

Atentemos para o mas, que marca um discurso dividido, estabelecendo uma ruptura entre o antes e o depois da educação formal. No entanto, quando diz que tem uma visão melhorzinha, percebemos, no diminutivo, um efeito de sentido pejorativo, que nos permite dizer que não houve essa ruptura. (idem, 2009, p.21).

Ainda, tomo por referência um segundo artigo, no qual discutimos a obra Quarup, de Antonio Callado, na relação com discursos sobre os indígenas na cidade (cf. BORGES \& MIRANDA, 2007).

Outro aspecto determinante do objeto da tese pode ser fundado na reflexão: mesmo que muitos indígenas estejam "integrados” à sociedade não índia, há uma delimitação, uma "fronteira" no discurso do "branco" que se inscreve no enunciado, "lugar de índio é na aldeia” (cf. BORGES, 2006).

Assim, fui percebendo o quanto a relação sujeito/cidade é, de fato, um espaço movente, dinâmico, um universo opaco chamando à interpretação; a cidade expõe as diferenças, e nos expõe ao cruzamento de sentidos heterogêneos, ao contato com o Outro. O Outro=corpo do sujeito enredado no corpo da cidade, durante o percurso dos estudos desenvolvidos, coloca-se como essa materialidade complexa que busquei interpretar na dimensão discursiva dos recortes analisados.

A cidade incorpora o índio, criando uma espécie de naturalização, no entanto, inscreve-se na materialidade linguística, uma incorporação coisificada, negada, explorada, despessoalizada, pois o indígena não é um indivíduo no convívio social, ou faz parte de um cenário, como "decoração", ou objeto "jogado por todo canto onde não deveria estar" ou é usado como freguês (em determinados estabelecimentos: mercados, restaurantes, hotéis), considerando que, mesmo numa relação comercial, há os que negam o Xavante como freguês.

Por outro viés, instaura-se a contradição, pois o corpo da cidade, também, vai sendo marcado pelas impressões do corpo indígena, empiricamente e na memória (por muito tempo a "Praça dos Garimpeiros" - fotos a e b - ainda será dita como a "Praça dos índios”). Outras marcas passam a ser inscritas, como, por exemplo, em um nome impresso numa placa de rua "Rua Xavante", em uma pintura que decora um muro, em uma escultura de um artista, no nome da maior empresa de ônibus do lugar, "Viação 
Xavante", na fachada que nomeia uma autoescola "Auto Escola Xavante" e, propriamente, na presença viva, frequente, desses sujeitos que se movimentam pela cidade.

A experiência de vida urbana fica inscrita, no próprio corpo daquele que a experimenta e, dessa forma, também o define, mesmo que inconscientemente. $\mathrm{O}$ corpo material de linguagem, social e simbólico produz sentidos e é significado em processos complexos que dizem respeito à identificação, subjetivação, à história, à espacialização.

Significa, ainda, na relação com a escolha do objeto, a leitura que fiz do texto "Selva de Pedra", de Pereira (2007 p. 40-49), que apresenta alguns dados interessantes. De início, a autora anuncia Sem perder a identidade, índios trocam a aldeia pela cidade e aderem à modernidade tecnológica. Em outros pontos da escrita, ela aborda a presença dos povos indígenas nas cidades, na relação com a ausência deles no imaginário, principalmente, dos jovens. Apoiando-se em dados do IBGE, a autora registra que existem no Brasil 703 mil índios e que 52\% dessa população, autodeclarada, moram em cidades. Segue "evidenciando" a forte relação entre cidade, indígenas e meios de comunicação, como internet e demais tecnologias.

Em uma escola do interior do estado da Bahia, uma professora promoveu um debate com alunos de idade entre 15 e 17 anos e o resultado, exposto na sequência discursiva abaixo, identificada por $(\mathbf{Y})$, encontra os discursos que enredam o Xavante em Barra do Garças, de acordo com os materiais que analisei: entrevistas realizadas com sujeitos barra-garcenses ou moradores da cidade, identificados por $(\mathbf{P})$ acompanhados dos numerais arábicos 1, 2, 3..., com acadêmicos (as) de diversos cursos do, na época, “Campus" Universitário do Araguaia-MT, de Barra do Garças, desde o ano de 2007, identificados por (A), também acompanhados dos numerais arábicos 1, 2, 3...que podem se repetir quando necessário. $\mathrm{O}$ mesmo procedimento será utilizado para identificar notícias sobre acontecimentos que envolvem os Xavante na cidade, publicadas no Jornal Online Olhar Direto (J) e respectivos comentários (C) e notícias seguidas de comentários de internautas da rede Índios Online. Vejamos o Recorte 1:

\section{Recorte 1}

(Y)-Durante o debate em sala e em avaliação oral, o comentário predominante: "Índio que mora em cidade não é índio!". Segundo o grupo o que eles pensavam sobre os povos indígenas não correspondia ao texto trabalhado, o que trouxe a superfície outro preconceito que está ligado à idéia 
de transitoriedade das sociedades indígenas. Já que durante todo o processo de colonização, Império e República as diversas etnias indígenas foram tratadas como transitórias, ou em vias de integração com a sociedade nacional. Sendo apenas reconhecida a pluralidade cultural destas etnias e o direito a terra e a educação diferenciada na Constituição de 1988.http://www.uesc.br/eventos/cicloshistoricos/anais/aretuza_da_cruz_silv a.pdf. Acesso em janeiro de 2011.

(A1)Pra mim esses que já estão muito tempo nesse vai volta já deixou mesmo de ser índio, não conformo com esse tratamento diferenciado...

(A3)Eles aproveitam de gente como a senhora, mais são mais espertos do que muitos brancos sem vergonha...virou branco da pior espécie. Não dou trela de jeito nenhum.

(A5)Tudo igual, tudo farinha do mesmo saco, na verdade os portuguêis não fez o serviço direito e agora a gente tem que viver com essa praga

No processo discursivo, os discursos que circulam em relação aos Xavante, no espaço da pesquisa, mantendo as especificidades do povo e da cidade, assemelham-se aos que ocorrem com outros povos, por isso, considero a relevância de fazer ecoar, aqui, vozes indígenas de diferentes etnias, à frente, para dialogar com o recorte acima e formular a análise, ou seja, quando indígenas enunciam que não deixam de ser índios por estarem na cidade, produzem o efeito de afirmação do discurso: índio deixa de ser índio quando vem para a cidade. Esse discurso parece natural, evidente, por efeito da ideologia. A interpelação ideológica é tão eficaz que não se questionam os sentidos que são produzidos. Por exemplo, está naturalizado que os povos indígenas "são preguiçosos", "são ladrões", "são invasores de terras dos fazendeiros", "deixam de ser índios quando vêm para a cidade".

O recorte 2 que segue, resguardando os nomes próprios e mantendo o nome da etnia, por exemplo: Makuxi (até porque é assim que costumam se dizer: "nós índios Makuxi", "nós índios Xavante") traz comentários de índios internautas de várias etnias, inclusive de um Xavante, sobre um texto intitulado: Estou na cidade e continuo sendo índio, publicado na rede Índios Online. Mantive o texto tal qual foi publicado, mudando apenas a formatação e tipo de fonte, de modo a se adequar às exigências estruturais deste trabalho. Acrescentei, ao final do recorte, uma resposta de um índio Pareci, dada a uma das questões que lhe foram feitas numa entrevista publicada na Revista

\section{Brasileiros de Raiz ${ }^{6}$.}

\footnotetext{
${ }^{6}$ Entrevista de Málcia Afonso com Daniel Matenho Cabixi, do povo Paresi, intitulada: "Vivendo entre dois mundos sem perder a identidade", In: Revista Bimestral da RRCK Comunicação \& Marketing, Ano I, $\mathrm{N}^{\circ}$ 1, abril/maio de 2011. Brasília/DF.
} 


\section{Recorte 2}

a) Estou na cidade e continuo sendo índio

Texto postado em 06 dezembro 2010, por A. Makuxi

A maioria dos indígenas que vive nas cidades sofreram e sofrem discriminação e preconceito. Em muitos casos o discurso preconceituoso vem acompanhado do senso comum, "índios é o que vive na mata, que anda pelado, que não tem veículo automotivo..." enfim, esse fato foi discutido na cidade de Boa Vista através da Organização dos Indígenas da Cidade - ODIC, essa organização está lutando com unhas e dentes para barrar essa margem de preconceito. $O$ fato a questionar é: os indígenas vieram para a cidade? ou a cidade que chegou para os indígenas ? Por que assim, pois vejamos, a cidade está cercada pelas comunidades Indígenas e nela se encontram aproximadamente 30 mil indígenas. Muitos deles vindo de outros países vizinhos. Segundo o Professor Reginaldo Gomes de Oliveira, da Universidade Federal de Roraima, aqui onde é a atual Cidade de Boa Vista era uma Comunidade Indígena Macuxi, e o nome seria kuwai Krî, quequer dizer Terras de Buritizais. Essa mesma História se repete nas reuniões da ODIC, e também nos discursos de alguns ãnciões de comunidades do Interior do Estado. Então Boa Vista foi implantada em cima de uma Comunidade Indígena, e o melhor é uma Comunidade Indígena, e a maior do Estado. Pode ser dizer que a maior aldeia de Roraima é Boa Vista, sem pingo de dúvida. De acordo com a História do não-índio a cidade criou-se a partir de uma Fazenda, o que ao se questionado com alguns anciões de comunidades, eles afirmam que tinha sim uma fazenda, mais não a que se tornou Boa Vista. O fato de eu está na cidade, usar celular, roupa, calçado, ir para a universidade, passear nas praças, não me tira a identidade indígenas, aliás eu na cidade estou apenas visitando parentes, o que significa que aqui na cidade eu me sinto como na minha comunidade, só que agora aqui é uma comunidade onde se tem vários Povos Indígenas e não Indígenas.

\section{b) Comentários de internautas indígenas}

1) Postado em 07 de dezembro de 2010 às 06h34min, por P. Pankararu Infelizmente isso ainda acontece, eu ja passei por situações semelhantes, na universidade me olhavam e falavam indígenas estudando na universidade, cursando uma graduação, especialização, eles ainda têem uma visão de 510 anos atraz, não perceberam que o mundo muda, tudo muda, tudo se transforma, nada é permanente, pois buscamos mecanismos para ajudar nossas comunidades de alguma forma. Agora estamos estudando, nos formando, temos cursos superiores, e competimos com os não indios de igual para igual e usamos essas novas tecnologias sim, afinal não estamos isolados do mundo, também somos pessoas, seres inteligentes, somos seres humanos. A unica diferença é a nossa cultura! Então meu parente A. Makuxi os não índios ainda nos fazem essas perguntas pq não conhecem a nossa história, a nossa realidade, quando nos fazem alguma pergunta desse tipo é pura ignorância mesmo falta de conhecimento!

2) Postado em 05 de janeiro de 2011 às 9h43min. L. C.. Xavante

Gostei tanto do post. Parabéns A. Makuxi. Passei a seguir o blog. Essa discussão não é nova e me toca profundamente, desde que comecei a "andar com as próprias pernas". Há pessoas que não conseguem, mesmo, olhar para o outro como semelhante, seja índio, negro, árabe, enfim... Não reconhecer no outro a mesma vida que pulsa em nós mesmos me parece a pior ignorância possível e creio que daí provém os maiores dramas, os mais cruéis desmandos. Eu continuo índio sempre. Por esse humilde comentário entrego a você, como representante dessa luta e de todos os povos indígenas, desse e todos os cantos do mundo, meu mais profundo 
agradecimento pela resistência e humildade na luta pelo fim da discriminação e pelo reconhecimento de uma só humanidade.

4) Postado em 05 de abril de 2011 à 18h10min. Por M. Tukana

Primeiramente parabéns pelo post, sai da minha aldeia faz 10 anos, mas nunca deixo de ser índia , continuo fazendo minha comidinha "mujeca", infelismente as pessoas tem essa idéia ainda, que índio anda nu, vive na oca e que come gente, é absurda tamanha ignorância das pessoas, é claro que existem várias tribos e etnias, com diferentes culturas, não deveriam generalizar. Além disso somos capazes de fazer qualquer coisa e aprender como qualquer um. Concordo com L. C. nunca deixaremos de ser índios, eu tenho orgulho de ser índia, pelo menos sabemos de onde viemos. Abraços!!http://www.indiosonline.net/estou-na-cidade-e-continuo-sendoindio/. Acesso em maio de 2011.

c)Entrevista da Revista "Brasileiros de Raiz"

Entrevistadora: Há quem considere que quando o índio absorve costumes externos deixa de ser índio:

Cabixi: Não concordo com essa visão. Em uma das assembléias, nas quais estive uma das lideranças indígenas fez a seguinte afirmação: "posso ser o que você é sem deixar de ser o que sou". Quer dizer que a partir do momento que nós indígenas temos plena consciência deste ditame, naturalmente poderá conceber todas as influências que ele tiver dentro do seu contexto natural. Ele vai saber separar o joio do trigo e se manter índio.

Em relação às sequências que trazem o discurso de si e não o discurso sobre, é importante ainda afirmar que há índios na rede, sim. As palavras de Leal comportam o que eu gostaria de dizer sobre esse acontecimento discursivo:

\begin{abstract}
A maré virtual não é só para brasileiros descobridores. Ou seja, no pretenso tudo da trama www, pode-se divisar não uma esfera sem bordas e plana, mas heterogeneidades e desigualdades de várias ordens a um clique. Em duas palavras: há sítios em que circulam não os discursos sobre, mas o que dizem os índios de si, da terra, da velha disputa com os brasileiros. (LEAL, 2011) ${ }^{7}$.
\end{abstract}

A respeito do uso do espaço virtual por diversos povos indígenas, recorro ao artigo: "Vozes indígenas na rede digital: análise discursiva de blogs, sites e comunidades" no qual a autora considera que, com o surgimento e popularização da internet, os povos indígenas contam com um espaço de enunciação privilegiado, para fazer circular sentidos interditados e/ou silenciados, ao longo da história. Para maiores detalhes, conferir Ferreira $(2012)^{8}$ :

Assim como Leal (idem) e no convívio, estudos, discussões com Ferreira (19832012) navegamos pelo universo virtual, a fim de investigar como circula o discurso indígena nesse espaço. Sobre o discurso de que o índio deixa de ser índio quando vem para a cidade, como pode ser conferido no recorte 2 , vi funcionar, justamente o contrário, desde o título do texto que gera os comentários.

\footnotetext{
7“Os índios, a terra, os brasileiros”. In:

http://www.discurso.ufrgs.br/anaisdosead/5SEAD/SIMPOSIOS/MariaDoSocorroPereiraLeal.pdf. Acesso em janeiro de 2012.

${ }^{8}$ FERREIRA, L.L.."Vozes indígenas no ciberespaço: funcionamento discursivo de blogs". http://www.iel.unicamp.br/revista/index.php/seta/article/viewFile/1298/1495. Acesso em janeiro de 2012.
} 
O meu interesse não é definir quem é índio, ou onde deve ficar o índio, mas esse discurso é, também, fundamental para se pensar o processo de identificação/subjetivação desse sujeito no espaço urbano.

Reitero que, historicamente, por efeito da memória discursiva, existe um imaginário de índio materializado, parafrasticamente, no recorte de comentários, que corrobora com o imaginário de que "lugar de índio é na aldeia" e/ou "índio que mora em cidade não é índio". Índios é o que vive na mata, que anda pelado, que não tem veículo automotivo... (A. Mackuxi); eles ainda têm uma visão de 510 anos atraz,não perceberam que o mundo muda, tudo muda, tudo se transforma, nada é permanente (P. Pankararu); Essa discussão não é nova e me toca profundamente. (...) Eu continuo índio sempre. (L. C. Xavante); mas nunca deixo de ser índia (...) nunca deixaremos de ser índios (M. Tukana); Há quem considere que quando o índio absorve costumes externos deixa de ser índio (entrevistadora).

Pelo efeito de evidência, a imagem de índio do passado vai se mantendo, mas, se por um lado, se repetem e se impõem os sentidos carregados de negatividade em relação aos povos indígenas, por outro, percebem-se outros sentidos diferentes na disputa por espaços de significação, o que, sob o meu parecer, aponta para um deslocamento discursivo, sintoma de que não estamos fadados à reprodução e à fixidez dos sentidos.

Como em outros trabalhos, tal imaginário faz parte de uma discursividade fundada no discurso da colonização. No recorte em pauta, identificamos: preconceito, constrangimento, humilhação, discriminação, desumanização, invisibilidade, como nos destaques das sequências discursivas de vozes indígenas:

(Makuxi) A maioria dos indígenas que vive nas cidades sofreram e sofrem discriminação e preconceito

(Pankararu) eu ja passei por situações semelhantes, na universidade me olhavam e falavam indígenas estudando na universidade, cursando uma graduação, especialização.

(Pankararu) afinal não estamos isolados do mundo, também somos pessoas, seres inteligentes, somos seres humanos

(Xavante) Há pessoas que não conseguem, mesmo, olhar para o outro como semelhante

(Tukana) infelismente as pessoas tem essa idéia ainda, que índio anda nu, vive na oca e que come gente

Instalado no interdiscurso, o discurso do passado se materializa e atualiza, como, por exemplo, na base linguística dos enunciados: "índio não é gente", "índio é bicho", “índio não trabalha”, "índio não é como nós”, que retomam "índio selvagem”, “índio 
preguiçoso", "índio não é brasileiro" e outros que caracterizam o discurso da "descoberta" (cf. quadro abaixo). O discurso atualiza e determina a diferença, indicando quem é o sujeito que deve aprender a ser igual. No entanto, os Xavante falam a língua Portuguesa, vestem roupas, utilizam aparelhos eletrônicos, mas são rejeitados no espaço onde os "brancos" julgam ser os donos: o espaço da cidade, e, nessas condições de produção, funciona o discurso inverso, ou seja, devolver o "civilizado" para a aldeia, "voltar ao que era", "lugar de índio é na aldeia".

É possível dizer que o processo de rejeição aos povos indígenas vem se mantendo durante séculos e se efetiva pelos mecanismos mais variados, dos quais a linguagem, com a violência simbólica que ela representa, é um dos mais poderosos. $\mathrm{O}$ quadro abaixo ${ }^{9}$, de sequências discursivas, resultado da pesquisa, já referida, que nos levou para a tese é uma mostra discursiva dessa violência:

\begin{tabular}{|c|c|c|c|c|c|}
\hline $\begin{array}{l}\text { Famílias } \\
\text { Parafrásticas }\end{array}$ & $\begin{array}{l}\text { Estudantes } \\
\text { universitários } \\
\text { (EU) }\end{array}$ & $\begin{array}{l}\text { Estudantes } \\
\text { de Ensino } \\
\text { Médio } \\
\text { (EEM) }\end{array}$ & Pais(PA) & $\begin{array}{l}\text { Professores } \\
\text { (P) }\end{array}$ & $\begin{array}{l}\text { Profissionais da } \\
\text { educação(PE) }\end{array}$ \\
\hline $\begin{array}{l}\text { Índio é } \\
\text { preguiçoso }\end{array}$ & $\begin{array}{l}\text { (...) "tinha lixo pra } \\
\text { tudo quanto é } \\
\text { canto, e a gente foi } \\
\text { catar junto com } \\
\text { eles; (...) eles } \\
\text { sentaram e ficaram } \\
\text { olhando a gente } \\
\text { catar o lixo." }\end{array}$ & $\begin{array}{l}\text { "Índio é } \\
\text { vagabundo, } \\
\text { preguiçoso, } \\
\text { quer tudo na } \\
\text { mão." }\end{array}$ & $\begin{array}{l}\text { "índio gosta de tudo na } \\
\text { mão; trabalhar que é } \\
\text { bom, nada." }\end{array}$ & $\begin{array}{l}\text {...”eu vejo } \\
\text { que hoje o } \\
\text { índio eles tão } \\
\text { muito, assim, } \\
\text { preguiçoso" }\end{array}$ & \\
\hline $\begin{array}{l}\text { Os índios são } \\
\text { protegidos } \\
\text { pelo governo }\end{array}$ & $\begin{array}{l}\text { “Aí, o governo, né, } \\
\text { dá aquela } \\
\text { aposentadoria pra } \\
\text { eles hoje. Então, } \\
\text { nessa questão eu } \\
\text { particularmente } \\
\text { acho arbitrária.” }\end{array}$ & $\begin{array}{l}\text { "Faz tudo o } \\
\text { que quer } \\
\text { porque é } \\
\text { protegido." }\end{array}$ & $\begin{array}{l}\text { (...) "o índio ele tem uma } \\
\text { proteção muito } \\
\text { grande"... }\end{array}$ & & $\begin{array}{l}\text { eu num concordo, } \\
\text { porque o índio a } \\
\text { partir da hora que } \\
\text { ele nasce, ele tem } \\
\text { um salário, né, que } \\
\text { eles recebe do } \\
\text { governo, então eu } \\
\text { acho que não } \\
\text { deveria ser assim"... }\end{array}$ \\
\hline $\begin{array}{l}\text { Somos } \\
\text { descendentes } \\
\text { de } \\
\text { portugueses }\end{array}$ & $\begin{array}{l}\text { "As terras } \\
\text { brasileiras, no caso, } \\
\text { quando aqui } \\
\text { chegamos, já eram } \\
\text { dos índios." }\end{array}$ & $\begin{array}{l}\text { "Quando } \\
\text { aqui } \\
\text { chegamos } \\
\text { eles já } \\
\text { estavam } \\
\text { aqui." }\end{array}$ & $\begin{array}{l}\text {... “com o } \\
\text { descobrimento do } \\
\text { Brasil... menos mal pra } \\
\text { nós, né, porque a gente } \\
\text { ia ser só um monte de } \\
\text { índio; Já pensou se } \\
\text { fosse assim?! E com o } \\
\text { descobrimento... } \\
\text { melhor serfilho de } \\
\text { português do que ser } \\
\text { filho de índio." }\end{array}$ & & \\
\hline $\begin{array}{l}\text { Índio é bicho } \\
\text { (selvagem) }\end{array}$ & $\begin{array}{l}\text { "Muitas pessoas } \\
\text { acham que os } \\
\text { índios eles são } \\
\text { bichos su/ sujando } \\
\text { a cidade" }\end{array}$ & $\begin{array}{l}\text { "Índio } \\
\text { parece que } \\
\text { não é gente." }\end{array}$ & $\begin{array}{l}\text { (...) "a própria sociedade } \\
\text { trata o índio como um } \\
\text { animal" }\end{array}$ & $\begin{array}{l}\text { (...) “de certa } \\
\text { forma ele é } \\
\text { agressivo, } \\
\text { ele é por } \\
\text { causa do } \\
\text { instinto } \\
\text { dele." }\end{array}$ & \\
\hline
\end{tabular}

\footnotetext{
${ }^{9}$ Esse quadro faz ressoar o trabalho de mestrado, desenvolvido por Azambuja (2004) no qual a autora trabalhou com o imaginário sobre os Karajá. As entrevistas foram realizadas por Miranda (2004), minha orientanda de Iniciação Científica, e as análises estão publicadas em Borges \& Miranda (idem, 2008, p.31-32-33).
} 
É possível afirmar que, nacionalmente, o discurso sobre os povos indígenas, significativamente/historicamente, inscreve-se na homogeneidade e imprime a relação índios e mata/selva, portanto, a cidade não comporta índio.

O inevitável contato entre povos indígenas e não indígenas, desde a colonização do Brasil, e no espaço que se dá no ir e vir da aldeia para a cidade, é repleto de significações. Há muitos trabalhos que abordam o assunto como processo de “desagregação cultural”, aculturação, que torna o Outro igual, ou seja, o índio perde o próprio ser e passa a ser o Outro, na medida em que incorpora aquilo que é do Outro.

Não vejo esse espaço de relações como lugar empírico, mas como espaço de sentidos, no qual me inscrevo, procurando desvendar o processo de identificação do sujeito indígena Xavante na cidade de Barra do Garças.

Identificação, que, mesmo apontando, em determinados materiais, uma mudança de posição em relação à visão etnocêntrica europeia sobre eles, ainda é dominada pela visão preconceituosa, hierárquica e divisionista ${ }^{10}$, apresentada nas análises.

Como dizer da identificação de um corpo, o indígena, que existe, sendo expulso discursivamente de outro corpo, o da cidade, tomando espaço, ocupando, à força, isto é, mesmo sendo expulso discursivamente, fica ali entranhado. Os Xavante, pelo que venho conhecendo, tanto pela bibliografia quanto pela proximidade que se criou nas nossas conversas, principalmente, nos últimos três anos, são um povo forte, resistente, tanto que eles se autodenominam A'uwê Uptabi, que significa povo guerreiro.

Outro aspecto relevante, na tomada de decisão frente ao objeto, tem a ver com o corpo, considerando que, na materialidade do sujeito, o corpo significa. É em Orlandi (2012, p.83) que me sustento nessa entrada para a questão do corpo, ao dizer: "A significação do corpo não pode ser pensada sem a materialidade do sujeito. E viceversa".

O Xavante "in(corpo)rado" na cidade e, carregando as suas marcas, mesmo deslocado do imaginário geral de índio, em Barra do Garças e, certamente, em toda a extensão do País, é reconhecido pelas características físicas impressas na ordem do corpo, e que encontram, no imaginário constituído historicamente, o efeito de sentidos da memória discursiva: cabelos lisos, pele "vermelha", ausência de pelos, tronco largo,

\footnotetext{
${ }^{10}$ Sobre essa visão, analisamos o enunciado "lugar de índio é na aldeia" sob a organização de famílias parafrásticas, num artigo publicado In: Estudos dicursivos em Mato Grosso: Limiares, EdUFMT, (2008).
} 
características somadas a determinados traços culturais, como, por exemplo, corte de cabelo e, ainda, tipos de adereços, como o brinco Xavante, ou a gravata de algodão usada em determinados rituais e que muitos fazem questão de mostrar, mesmo em situações cerimoniais não índias. Mesmo modificado, "incompleto", ele é reconhecido como índio.

A prática discursiva está diretamente relacionada com a formação ideológica. Os sujeitos já estão inscritos numa Formação Discursiva, que foi construída historicamente. Observemos a seguir o recorte de sequências das entrevistas com acadêmicos do CUA/UFMT (A):

(A1) Quando a gente era criança a gente vivia convivendo com os índios; só que eles são muito espertos, e a minha vó mesmo dizia que não pode dá mole eles são que nem bicho, é por isso que/ aí que tá o esquema de hoje eu não gostar de índio, sabe, porque eles robam a gente, sabe, eles enganam a gente. Os que estudam na cidade que já tem muito tempo, até conversam na língua portuguesa já mudaram um pouco...é...mais é índio né prof.?

(A2) Índio quer tudo na mão; trabalhar que é bom, nada, não são igual que a gente que dá duro se quiser estudar e sempre foi assim, no meu modo de viver não tem lugar pra índio, eles não vão ser assim como nós.

(A3) O índio, hoje, ele já era assim bem... podemos dizer assim bem português, um quase português, um quase índio brasileiro, ele fazia faculdade de Direito, lá em Brasília (...) Então, assim, quando o índio ele já tá bem... dentro da nossa cultura, até dá pra conversar; agora quando ele é um índio que mora na aldeia, dificulta né? (...).

Dentre outros aspectos, ressalta-se a temporalidade marcada nesse recorte de sequências que as divide num antes: "quando a gente era criança", "e sempre foi assim" (continuidade, foi/é assim), "ele já era assim", e num agora: “aí tá o esquema de hoje eu não gostar de índio", "e sempre foi assim", "o índio hoje”, no entanto regularizam/atualizam um discurso: "índio é ladrão", "índio é selvagem”, “índio é preguiçoso", mesmo incorporando a nossa cultura não chega a ser brasileiro: " um quase português, um quase brasileiro".

Compreender a temporalidade significa atentar para as diferentes temporalidades inscritas no discurso, mostrando as relações entre elas e os efeitos de sentido que aí se produzem. A Análise de Discurso não trata da temporalidade empiricamente, num tempo cronológico, mas por meio dos processos discursivos. Conforme Nunes (1996), um discurso remete a outros discursos dispersos no tempo; ele pode simular um passado, reinterpretá-lo, projetá-lo para um futuro, fazendo emergir efeitos temporais de diversas ordens. O autor (2005) desenvolveu um trabalho acerca do discurso sobre as línguas indígenas, em meados do século XIX, pensando a temporalidade, a interpretação 
e a compreensão. Ele estudou no dicionário de Gonçalves Dias (1858) as definições de diversos verbos no pretérito, assim como o autor escreve:

\begin{abstract}
O aparecimento das marcas de pretérito, quando considerado no percurso de arquivo, desloca a temporalidade em relação a dicionários anteriores, como os dos jesuítas, que descreviam a língua em uso (os índios dizem X, quer dizer, Y) em uma prática de tradução-interpretação na qual prevalecia o tempo presente (ao mesmo tempo em que a historicidade dos mitos e da tradição oral indígena era silenciada).

A marca do pretérito nos dicionários do Império estabelece a língua indígena como pertencente a um passado lingüístico: trata-se do tupi antigo ${ }^{11}$, língua "dos antepassados brasileiros", romanticamente simulada. Esse é um primeiro gesto de interpretação que se depreende da escrita do dicionário.Tal gesto está ligado a uma série de discursos que nessa conjuntura abordam o índio como antigo e primitivo: na escrita da história do Brasil, na literatura, assim como na história das línguas indígenas empreendida por Gonçalves Dias (s.d.). (grifos nossos).

http://www.ufrgs.br/analisedodiscurso/anaisdosead/sead2_simposios.html.

Acesso em dezembro de 2010.
\end{abstract}

É preciso estar atento aos mecanismos ideológicos que silenciam outras possibilidades de interpretações. $\mathrm{O}$ autor segue analisando que a imagem do tupi antigo torna inacessível o tempo presente das línguas indígenas existentes, assim como as varianças dessas línguas.

Como Nunes (idem), entendo que a imagem de indígenas do passado se repete como modo de impedir que se enxergue, considere as mudanças históricas produzidas no/pelo contato, que as condições de produção na sociedade atual são outras e que os índigenas, no presente, também, são outros.

Percebo que há uma tentativa de deslocamento, de mudança de posição no discurso, mas também impedida de significar pelo efeito de imaginário do passado inscrito na conjunção quase (algo que não é possível acontecer) "um quase brasileiro"; há um intervalo, uma temporalidade significada na palavra quase que produz a imposibilidade de um índio tornar-se um brasileiro na atualidade. Não se atentar para esse desdobramento pode levar a interpretar sem compreender.

Sou levada a dizer que esse quase é espaço dos acontecimentos entre a aldeia e a cidade, produzido pela interpelação do discurso urbano; poderíamos interpretar que há nesse espaço discursivo duas memórias no embate, duas Formações Discursivas: a FD indígena e a FD do urbano, afetada pelo discurso do colonizador.

\footnotetext{
${ }^{11}$ Cf. análise do Vocabulário na Língua Brasílica (J. H. Nunes. Discurso e instrumentos lingüísticos: dos relatos de viajantes aos primeiros dicionários. Tese de doutorado. Campinas, IEL-Unicamp, 1996).
} 
Se retomamos Nunes (ibidem), vemos a complexidade de subjetivar-se um sujeito indígena, quando, pela temporalidade, são silenciados seus mitos, suas línguas, encontrando no nosso material, a sua identificação (é um quase índio brasileiro).

Explorando, ainda, o recorte, chamamos a atenção para o discurso reiterado e preconceituoso "índio é ladrão", "índio é selvagem”, "índio é preguiçoso", que se inscreve nas sequências discursivas.

De acordo com Orlandi (2000), o preconceito está na origem da estagnação social e histórica. É uma forma de censura para impedir o movimento, a respiração dos sentidos e, consequentemente, de novas formas sociais e históricas na experiência humana. A autora amplia a reflexão:

\begin{abstract}
Os sentidos não podem sempre ser os mesmos, por definição. Os mesmos fatos, coisas e seres tem sentidos diferentes de acordo com suas condições de existência e de produção. No entanto, há um imaginário social, que na história, vai constituindo direções para esses sentidos, hierarquizando-os de acordo com as relações de sentidos, e logo, as relações sociais. (...) O preconceito não vem de um processo consciente, e o sujeito não tem acesso ao modo como os preconceitos se constituem nele. Vem pela sua filiação a redes de sentidos que ele mesmo nem sabe como se formaram nele. (2002, p.197).
\end{abstract}

Entendo que, nessa perspectiva, o preconceito é uma discursividade que se impõe sem sustentação em determinadas condições de produção; essa discursividade, como vou confirmando, é seguramente mantida por relações imaginárias atravessadas por uma não permissão do dizer que apaga (silencia) sentidos e razões da própria maneira de significar.

Quero dizer, assim como Orlandi (idem), que o preconceito se realiza em cada sujeito que diz, mas não se constitui no indivíduo em si; ele é de natureza históricosocial e se faz nas relações sociais, pela maneira como essas relações significam e são significadas, e os sentidos da relação constitutiva do sujeito com o espaço e vice-versa é uma materialidade produtiva para compreender o funcionamento do preconceito.

Sabemos que a subjetividade pode se alojar em mecanismos linguísticos específicos, não sendo possível explicá-la estritamente por eles; assim, é pelo viés da história, da ideologia, da memória marcados nas materialidades significantes, que sigo buscando entender discursivamente, indícios dos limites presentes no discurso dos sujeitos da pesquisa.

(A4) Eles vive na redoma deles, só ali na sinuquinha do Bar do Jura, agora a vida dessa gente é a sinuca e a coca-cola...eu heim...fico até curiosa de saber o que que eles pensa, se pensa né, eu passo perto e fico olhando eles. (A5) quero distância desse povo, tenho até medo de chegar perto e eles colar em mim. Que saber? É me melhor...eu nem vejo. 
(A6) eles lá e eu aqui, bem longe de mim, prefiro não lembrar que a cidade tá infestada dessa gente...

(A7) corto volta deles, Deus me livre professora, a $\mathrm{Sr}^{\mathrm{a}}$. inventa moda, eu não quero nem ver(risos).

(A8) devia ter ficado lá atrás, o tempo devia ter parado do jeito que era antigamente, não quero saber desse povo de jeito nenhum".

Aqui a memória convoca o exótico, por um lado, e, por outro, repete o imaginário de "selvagem", de "bicho" que se mantém se pensa né ; é bicho, logo, não pensa. Essa discursividade se inscreve no discurso do distanciamento tenho até medo quero distância desse povo, eles lá e eu aqui, corto volta quando vejo, devia ter ficado lá atrás (...) do jeito que era antigamente e, assim produz um apagamento sobre a possibilidade do convívio no presente.

Em (A6) o efeito de sentidos extrapola o desejo do distanciamento do sujeito índio para os sentidos de doença pelo adjetivo atribuído à cidade: "cidade infestada", como se a presença indígena disseminasse uma epidemia e, no caso, é preferível esquecer. Esse dizer corrobora com (A5) tenho medo chegar perto e eles colar em mim. O querer/desejo se volta para o passado, o tempo devia ter parado para os índios para que ficassem como antigamente. Interpretamos aí uma inversão da história/memória: no contato com os europeus, os povos indígenas sofreram com as epidemias, agora eles são a doença, ou caso interpretemos infestada por praga=erva daninha que se espalha, da qual é preciso manter distância, inclusive temporal, retorno ao antigamente, funcionando como já analisado, em que a temporalidade não significa o tempo passado, empírico, mas trabalha os sentidos da impossibilidade do índio no presente, impede o acontecimento do contato, da mudança, do indígena na cidade.

Os dêiticos: "Eles", “dessa gente”,"desse povo",“deles” que reformulam índio, convergem os sentidos para a produção do distanciamento, da separação, da exclusão, estabelecendo a diferença, deixando de fora, impedindo o pertencimento ao povo brasileiro, à cidade. Esse é um modo eficaz da negação.

Em (A6) Não lembrar que, (A7) não quero saber, (A8) não quero nem ver, inscreve-se, agora, de outro modo, a negação como efeitos de sentido que permitem interpretar a invisibilidade em relação aos povos indígenas. $\mathrm{O}$ apagamento, inclusive, da possibilidade de conhecer esse Outro, próximo $\mathrm{X}$ distante, presente $\mathrm{X}$ ausente. Seguimos construindo a análise, mostrando a complexidade constitutiva desse sujeito carregado de significações diversas e contraditórias. 
Pela negação podemos encontrar em uma formulação a coexistência de discursos antagônicos.

\begin{abstract}
A negação diz respeito à presença do oposto no fio do discurso. Mais do que isso, "a negação é um dos processos de internalização de enunciados oriundos de outros discursos, podendo indicar a existência de operações diversas no interior do discurso em análise. Em suma, essa construção evidencia a presença do discurso-outro" (INDURSKY, 1997, p.213).
\end{abstract}

Esse discurso-outro se faz presente no discurso-um sob diferentes modos e é nesse sentido que busco analisar o funcionamento da negação pela memória, os sentidos estabelecidos e que entram no esquema $\mathrm{X}$ não é $\mathrm{Y}, \mathrm{X}$ não é $\mathrm{Z}, \mathrm{X}$ não é $\mathrm{W}$, constroem, pela negação, pela ausência, a imagem do que seria $X$.

A negação ao índio funciona discursivamente trazendo o discurso-outro para o espaço do discurso-um, pelo trabalho do sujeito na língua, fazendo ambos os discursos coexistirem, mediante um conflito instaurado na formulação, acerca da construção do imaginário do que poderia ser aproximação, o convívio com os Xavante naquele espaço. É pela negação de tudo que não se quer que o sentido é estabelecido, ainda que não formulado. Podemos extrair das sequências em discussão:

\title{
Prefiro não lembrar $X$ eu lembro Não quero saber $X$ eu sei Eu nem vejo Xeu vejo
}

O processo de identificação do sujeito Xavante que frequenta a cidade de Barra do Garças é produzido pela instauração de uma temporalidade, que atualiza e determina o espaço do outro, por meio do preconceito, da invisibilidade e, ao mesmo tempo, projeta esse sujeito para o lugar do excluído, discriminado, marginalizado, interditado, destinado a voltar para o lugar de onde veio, no entanto, ele está, cada vez mais, presente na cidade.

As sequências de algumas entrevistas, nos possibilitam afirmar que, de fato, muitas pessoas da população de Barra do Garças $(\mathrm{P} 1,2,3)$ quando interrogadas sobre a presença dos Xavante na cidade, têm a ilusão de origem de que expressam o "seu" ponto de vista. Elas se inscrevem no que se pode chamar de juridismo, ou interpelação pelo discurso jurídico.

Pechêux (1975) considera que não existe discurso sem sujeito, nem sujeito sem ideologia. Assim, não é possível entendê-los separadamente. Por mais que trabalhemos a autoria como ilusória, a ideologia como enganadora e o discurso como materialização da ideologia, não podemos desprezar a relação que se estabelece entre eles e o sujeito. 
Para mostrar esse funcionamento, chamo a atenção, no recorte de sequências discursivas, primeiramente, para algumas expressões como: "penso que", "eu acho que", "no meu pensar", “na minha opinião", que dão a ideia de que está se falando de uma posição e que esse dizer só pode ser dito desse modo.

P1) Penso que, agora já são cidadãos comuns, igualmente a gente, não tem mais jeito de voltar atrás, tão tudo aí falando português...

P2)Eu acho que também eles devem ser julgados na nossa lei como cidadão, tem uns né? Porque tem os que ainda ficam na aldeia.

P3)Bom, no meu pensar eu acho que sim, eu acho que ele deve ser tratado como o branco, já num ta aí, vivendo aí que nem todo mundo na cidade

P4)Na minha opinião,tem que ser na forma da lei, essa coisa de porque é índio é incapaz e inocentam, nada a ver, toda vida eles são esperto mesmo, mas precisa de cidadania assim como qualquer um.

Na perspectiva trabalhada, o sujeito constrói seu dizer nas bases do imaginário com o qual ele se identifica, isto é, o imaginário que ele constrói sobre seu espaço, e o espaço do Outro tem por função sustentar os processos de identificação e é somente por um trabalho de desarranjo/rearranjo desses processos que a identidade pode estar sempre em formaçãoltransformação.

O grupo de sequências em análise produz uma reformulação/paráfrase do dizer que abre para a interpretação de que os sujeitos aí se inscrevem pela $1^{\mathrm{a}}$ pessoa do verbo em uma posição de cidadãos entendida pelo lugar cedido ao Outro. É em relação a si que se atribui o espaço ao índio, na ilusão de domínio de si: "penso que”, "eu acho que", "no meu pensar", "na minha opinião". Os sujeitos assumem um engajamento discursivo para produzir, a partir da "sua" posição, ou seja, a de cidadão e assim projetam a "cidadania" para os índios, por isso mesmo, sustentando-se no discurso jurídico. Neste caso, o sujeito é interpelado pelo discurso jurídico, funcionando pela comparação para "se realizar" a cidadania: "agora já são cidadãos comuns", "igualmente a gente", "eles devem ser julgados na nossa lei como cidadão", "ele deve ser tratado como o branco", "aí que nem todo mundo na cidade", "precisa de cidadania assim como qualquer um".

De acordo com Zoppi-Fontana (idem) o gesto impresso nas sequências discursivas pode ser considerado como um acontecimento lingüístico no qual os movimentos de interpretação se representam como "tomadas de posição" do sujeito de 
enunciação. O conceito de acontecimento linguístico a autora busca em Guilhaumou (1997) o qual é pensado como momento de emergência de formas singulares de subjetivação. Ainda é a autora (ibidem, s/nº que afirma:

[...] explicitar/trabalhar a eficácia ideológica de determinado corpus em análise implica descrever as operações de formulação que constituem as sequências discursivas como reformulações presas na rede de enunciados (domínio de saber) e na rede de lugares enunciativos (modos de dizer/modalidades enunciativas) que inscrevem o sujeito no fio do discurso.

Os “cidadãos” barra-garcenses, embora se digam cidadãos, pela equivocidade da língua, distribuem, dividem os cidadãos em: "comuns", "brancos", "todo mundo da cidade", "qualquer um" e "índios" (uma vez que as sequências respondem à nossa pergunta sobre a consideração acerca da presença indígena na cidade).

Desse modo, a identificação do sujeito não é plena, pois as relações sóciohistóricas são afetadas pelo outro-Outro. Não é plena, porque há a incompletude do sujeito, da linguagem e há os equívocos na língua. E é nesses espaços de deslocamento, de desestruturação/reestruturação que se dão os processos de identificação do sujeito e as modalidades de subjetivação e que prescrevem as posições a serem ocupadas pelo sujeito, por meio do funcionamento da forma-sujeito.

Neste ponto, interessa dizer que, conforme o recorte em análise, o índio é cidadão pela permissão do não índio; ademais, é importante observar que há um conflito no dizer dos "cidadãos" entrevistados que quebra o discurso, mostrando a dificuldade de reconhecer o Outro como cidadão em a) "agora não tem mais jeito de voltar atrás...fala português"; o advérbio temporal, ainda que marque um presente, deixa interpretar um antes, ou seja, houve um intervalo na história (tempo para aprender a língua portuguesa), isto é, fala a língua, logo, é cidadão.

Em b) "tem uns né"? Porque "tem os que ainda ficam na aldeia"; aqui, o discurso divide os índios entre uns (indefinidos) e os que ainda ficam na aldeia (definidos pelo artigo, entendidos pelo ainda, na projeção de um futuro passível de mudança). Ainda é possível interpretar, nesse gesto de atribuição de cidadania, que ser cidadão no caso (b) é "ser julgado pela lei"; se sabemos que quem é julgado, é criminoso, então: índio é criminoso.

Em c) "ele deve ser tratado como o branco", "já num tá aí, vivendo aí que nem todo mundo na cidade", a questão que ressalta na divisão do sujeito índio, nessa sequência, é de tratamento e ocupação do espaço; é cidadão porque está na cidade (aî) e "deve ser" (verbo modalizador) tratado como o branco=todo mundo (universalizante). 
Por último, "tem que ser na forma da lei", "essa coisa de porque é índio é incapaz e inocentam", "nada a ver, precisa de cidadania assim como qualquer um", retoma-se a inscrição no discurso jurídico (na forma da lei e incapacidade), contudo negando esse discurso (nada a ver) e recuperando o imaginário de índio esperto (pejorativamente), mas- essa conjunção adversativa divide a sequência e possibilita, pela necessidade da cidadania, a inclusão do índio no conjunto indefinido de "qualquer um".

Em um dos seus "giros" Zoppi-Fontana $(2004)^{12}$, a partir da análise de materiais da imprensa e produzidos na universidade, aponta para uma convergência de funcionamentos que regularizam um processo discursivo universalizante e "privatizante", no que tange à relação com a cidade. Ela escreve que esse processo:

Perpassa instituições diferentes (mídia, imprensa, universidade) articula campos discursivos distintos (jurídico, administrativo, científico, político, pedagógico), constituindo de maneira imbricada, elementos de saber que se impõem na sociedade produzindo consenso, o "senso comum" do "cidadão comum" (...) que anseia levar "uma vida decente...nas metrópolis brasileiras"(...). Movimento perverso que nos leva da consciência universal à eterna vigilância e através dela à cidade "alerta" (idem, p. 110, grifo nosso).

Esses "fatos discursivos ${ }^{13}$ " situam as questões que me coloco para afirmar que, inserido na cidade e sofrendo seus efeitos, o sujeito se constitui num movimento entre/antes, isto é, entre/antes a/na aldeia e o/no espaço da cidade agora. Não chega a ser brasileiro, a cidadania é atribuída (condicionalmente).

Posso afunilar a trama discursiva, pensando esquematicamente, como segue:

\section{INDÍGENA NA CIDADE---------------RELAÇÃO COM O ESTADO BRASILEIRO \\ FORA DA CIDADE = NÃO CIDADÃO URBANO \\ DENTRO DO DIREITO}

DENTRO DO DIREITO

\section{NA CIDADE $=$ CIDADÃO COMUM}

\footnotetext{
${ }^{12}$ Texto no qual a autora no jogo de significações das cidades, em duas instituições que participam do processo de produção social dos sentidos (a imprensa e a universidade) analisa a miragem do "cidadão comum".

${ }^{13}$ Cf. (ORLANDI: 1996) que distingue as noções de dado e fato utilizadas pelas teorias de linguagem; a noção de fato permite desnaturalizar a relação com a realidade empírica, questionando a possibilidade de ter um acesso direto a dados "puros", independentemente da abordagem teórica assumida. Trabalhar na análise com a noção de fato implica partir do pressuposto de que todo recorte do real se constitui já como leitura, realizada a partir de uma determinada matriz teórica.
} 
O sujeito é consequência das discursivizações em torno dele, nas condições de produção em que se encontra. Ele é interpelado e funciona como efeito e como materialização das interpelações constitutivas da memória discursiva. É nesse movimento que se instaura a resistência, pois o povo Xavante interpela a cidade que o interpela.

O não índio significa, delimitando seu espaço e o espaço do Outro=índio, marcando-se, assim, em seu discurso, a diferença, a desigualdade, o preconceito, o distanciamento, a invisibilidade, a negação, a exclusão, a divisão, a brasilidade, a cidadania. Os efeitos interdiscursivos se materializam no encontro entre o passado e o presente, num terreno movediço, complexo, o qual exige muito estudo e análise para ser entendido, pois esses dizeres interpelam os Xavante a subjetivar-se, a identificar-se, a significar-se e produzir sentidos, a se olhar e se fazer olhar.

\section{Referências bibliográficas}

AZUMBUJA, E. 2005. Olhares, Vozes e Silêncios que excluem: estereótipos de índio. Cáceres-MT, Editora da Unemat.

BARONAS, R. L. 2008. Estudos Discursivos em Mato Grosso: limiares. São CarlosSP, Pedro \& João Editores/Cuiabá-MT, EdUFMT.

BORGES, A. A. C. 2006. "A constituição discursiva sobre o índio em Barra do Garças/MT: um paradoxo na praça" In: Revista Panorâmica Multidisciplinar, No 6 . Cuiabá-MT, EdUFMT.

BORGES, A. A. C.\& MIRANDA, F. L. A. 2007. "Discurso Literário e Realidade: encontro na interpretação de Quarup, de Antonio Callado" In: Revista Panorâmica Multidisciplinar, No 7. Cuiabá-MT, EdUFMT.

BORGES, A.A.C. "Para uma história das ideias linguísticas - uma reflexão sobre a resistência do povo Xavante pela língua". (In: Colóquio Internacional de Estudos Linguísticos e Literários (2010): Maringá, PR) C718 Anais CELLI - Colóquio de Estudos Linguísticos e Literários [recurso eletrônico] UEM-PLE, 2010. Disponível em:<http://www.ple.uem.br/ ISSN 2177-6350.

COURTINE, J-J. 2008. História do Corpo: As mutações do olhar - o século XX. Petrópolis-RJ, Vozes.

GADET, F. \& PÊCHEUX, M. 2004. A Língua Inatingível. Tradução: Bethânia Mariani e Maria Elizabeth Chaves de Mello. Campinas-SP, Pontes.

HASHIGUTI, S.T.Corpo de memória. Tese de doutorado. UNICAMP-IEL. 2008.

INDURSKY, F. 1990. "Polêmica e denegação: dois funcionamentos discursivos da negação'. Cadernos de Estudos Linguísticos, 19, jul/dez, Campinas-SP, Editora da UNICAMP, p. 117-122. 
LEAL, M. S. P. "Os índios, a terra, os brasileiros". In: http://www.discurso.ufrgs.br/anaisdosead/5SEAD/SIMPOSIOS/MariaDoSocorroPereira Leal.pdf. Acesso em janeiro de 2012.

NUNES, J. H. 2006. "Escrita e subjetividade na cidade". In: A Escrita e os escritos: reflexões em análise do discurso e psicanálise. Bethânia Mariani (org.). São Carlos-SP, Claraluz.

NUNES, E. S. 2010. “Aldeias urbanas ou cidades indígenas?”. Porto Alegre-RS, Espaço Ameríndio, Vol. 4, n. 1, p. 9-30, jan./jun..

ORLANDI, E. P. 1988. A Linguagem e seu funcionamento: as formas do discurso. São Paulo-SP, Brasiliense,.

RJ, Vozes. 1996. Interpretação, autoria, leitura e efeitos do trabalho simbólico. Petrópolis1996. "Exterioridade e Ideologia". In: Cadernos de Estudos Lingüísticos 30. Pp. 27-33. Campinas-SP, IEL/UNICAMP.

1997. "Um Sentido Positivo para o Cidadão Brasileiro", In: Sociedade e Linguagem. Campinas-SP, Editora da UNICAMP.

Pontes.

2001. Discurso e Texto. Formulações e Circulação dos Sentidos. Campinas-SP,

(1999) 2005. Análise de Discurso - princípios e procedimentos. Campinas-SP Pontes, UNICAMP.

2010. Discurso e Políticas Urbanas: a produção do consenso. Campinas- SP, Editora RG,

2012. Discurso em Análise: Sujeito, Sentido, Ideologia., Campinas-SP, Pontes, UNICAMP.

ORLANDI, E. P. (Org.). 1993. Discurso Fundador. A formação do país e a construção do país e a identidade nacional. Campinas-SP, Pontes,UNICAMP. UNICAMP.

(Org.). 2010b. Gestos de leitura: da história no discurso. Campinas-SP, Pontes,

. (Org.). 2011. Discurso, Espaço, Memória: Caminhos da identidade no Sul de Minas. Campinas-SP, Editora RG,

PAYER, M. O. 2005. "Linguagem e sociedade contemporânea: sujeito, mídia, mercado". In: Rua: Revista do Núcleo de desenvolvimento da Criatividade da UNICAMP/NUCREDI. Campinas-SP, $\mathrm{n}^{\circ} .11$, março.

2006. Memória da Língua: imigração e nacionalidade. SP, Escuta.

PÊCHEUX, M. (1969). 1990. “Análise automática do discurso (AAD-69)”. In GADET, Françoise \& HAK, Tony.Por uma análise automática do discurso, uma introdução à obra de Michel Pêcheux. Campinas-SP, Pontes, UNICAMP. 
. (1975). 1988. Semântica e discurso. Uma crítica à afirmação do óbvio. Campinas-SP, Pontes, UNICAMP.

PÊCHEUX, M. 1999. Papel da memória. In: Achard, P. et al. Papel da memória (Nunes, J.H., Trad. e Intr.). Campinas-SP, Pontes.

RODRIGUES, E. A; SANTOS,G.L.;CASTELlO BRANCO, L. K. A. (Orgs.). 2011. Análise de Discurso no Brasil: pensando o impensado sempre. Uma homenagem a Eni Orlandi. Campinas-SP, Editora RG.

SILVA, R. N. 2001. O universo social dos indígenas no espaço urbano: Identidade étnica na cidade de Manaus. 2001. 113 f. Dissertação (Mestrado em Antropologia), Universidade Federal do Rio Grande do Sul, Porto Alegre.

SOUZA, P. de. 2001. Espaços interditados e efeitos-sujeito na cidade. In ORLANDI, Eni P. Cidade atravessada: os sentidos públicos no espaço urbano. Campinas-SP, Pontes, UNICAMP.

ZOPPI-FONTANA, M. G. 1997. Cidadãos Modernos, discurso e representação. Campinas-SP, Pontes, UNICAMP.

1997. "Camelôs e o direito à cidade". In: Anais do $7^{\circ}$ Encontro da ANPUR: Novos recortes territoriais, novos sujeitos sociais: um desafio ao planejamento. Recife, MDU/UFPE. p. 1160-1179.

. 1999. "É o nome que faz fronteira". In: Indursky, F. (org) Os Múltiplos territórios da Análise do Discurso. Porto Alegre, Coleção Ensaios do CPGLetras/UFRGS.

2009. "Acontecimento, temporalidade e enunciação. Definições terminológicas e o fato novo na ciência". In: Cadernos de Estudos Linguísticos, v 51-1. Campinas: Instituto de Estudos da Linguagem, p.69-94.

2005. "Identidades informais: contradição, processos de designação e subjetivação", ZOPPI-FONTANA, M. Arquivo jurídico e exterioridade. In: GUIMARÃES, E. E PAULA, M. (Orgs.). Sentido e Memória. Campinas-SP, Pontes. 
Para citar essa obra:

Borges, Águeda Aparecida da Cruz. Relação sujeito indígena/cidade: analíses para a construção de um objeto de pesquisa. In: RUA [online]. 2014, no. 20. Volume II - ISSN 1413-2109. p. 73-95. Consultada no Portal Labeurb - Revista do Laboratório de Estudos Urbanos do Núcleo de Desenvolvimento da Criatividade.

http://www.labeurb.unicamp.br/rua/

Capa: disponível em http://static.panoramio.com/photos/large/21969578.jpg

Laboratório de Estudos Urbanos - LABEURB

Núcleo de Desenvolvimento da Criatividade - NUDECRI

Universidade Estadual de Campinas - UNICAMP

http://www.labeurb.unicamp.br/

Endereço:

LABEURB - LABORATÓRIO DE ESTUDOS URBANOS

UNICAMP/COCEN / NUDECRI

CAIXA POSTAL 6166

Campinas/SP - Brasil

CEP 13083-892

Fone/ Fax: (19) 3521-7900

Contato: http://www.labeurb.unicamp.br/contato 